\title{
Detection of Water-deficit Stress from Daily Sap Flow Profiles in Peach
}

\author{
Takayoshi Yamane $^{1 * * * *}$, Yoji Hamana ${ }^{1}$ and Mikio Nakano ${ }^{2}$ \\ ${ }^{1}$ Fruit Tree Research Division, Agricultural Technology Research Center, Hiroshima Prefectural Technology Research Institute, \\ Higashi-Hiroshima 739-2402, Japan \\ ${ }^{2}$ Graduate School of Life and Environmental Sciences, Kyoto Prefectural Univ., Kyoto 606-8522, Japan
}

Eight-year-old peach trees (Prunus persica (L.) Batsch cv. 'Hakuho' grafted on 'Ohatsumomo' peach rootstock), planted in $1500 \mathrm{~L}$ beds in a plastic greenhouse to avoid rain and groundwater effects, were used to evaluate the relationships among sap flow (SF), water-deficit stress parameters, and atmospheric conditions. Under a mild water-deficit stress condition, sap-flow velocity (SFV) decreased in the afternoon but not in the morning. Two indices were derived from the daily SFV profile: i) the slope of the regression line of SFV in the daytime (index C) and ii) the decreasing rate of SFV from the morning to each hour in the afternoon (index D). These indices showed higher correlation coefficients to the tree water status expressed by predawn leaf water potential $\left(\Psi_{\mathrm{PD}}\right)$ $\left(r^{2}=0.41\right)$ and maximum daily shrinkage of the trunk (MDS) $\left(r^{2}=0.58 * *\right)$ than to daily total SF (index A) and SFV at each hour in the daytime (index B). In a nonstressed condition, SFV was more highly correlated to photosynthetic photon flux density (PPFD) $\left(r^{2}=0.84 * *\right)$ than to temperature, relative humidity, and vapor pressure deficit (VPD). The correlation coefficients $\left(r^{2}\right)$ of indices with MDS and $\Psi_{\mathrm{PD}}$ increased to $0.77^{* *}$ and $0.92 * *$, respectively, when the SFVs of low light intensity $\left(<800 \mu \mathrm{mol} \cdot \mathrm{m}^{-2} \cdot \mathrm{s}^{-1}\right.$ of PPFD) were eliminated. The index which most precisely detected water-deficit stress was the decreasing rate of SFV from the morning (07:00-11:00 h) to any hour from 12:00 to 15:00 h with the elimination of SFV values when PPFDs were low.

Key Words: light intensity, predawn leaf water potential, trunk shrinkage.

\section{Introduction}

Irrigation of fruit trees is usually determined based on soil drying. Surface soil drying is often checked visually but rarely by tensiometer; however, the condition of part of the soil does not always match that of the whole soil in the root zone, because fruit tree roots are distributed at various depths depending on the soil type and floor management (Parker et al., 1993).

Irrigation by a plant-based method is a significantly better method than soil-based estimation to save water, maintain optimal plant growth and improve fruit quality (Jones, 2004). Predawn leaf water potential and midday stem water potential are traditional methods to measure plant water status; however, these measurements are

Received; November 30, 2010. Accepted; April 12, 2011.

This work was supported by Ministry of Agriculture, Forestry and Fisheries (Research project for utilizing advanced technologies in agriculture, forestry and fisheries, No. 18089).

*Corresponding author (E-mail: takayoshi.yamane@gmail.com).

** Present address: National Institute of Fruit Tree Science, NARO, Tsukuba 305-8605, Japan. destructive and labor intensive.

Nondestructive and automatic methods and instruments have been developed to measure plant water status. For example, plant growth measurements, such as daily stem or trunk shrinkage measurements, are taken by strain gauge (Link et al., 1998; Yamane et al., 2009) and linear variable displacement transducer (Goldhamer and Fereres, 2001); stomatal closure measurements by leaf temperature monitoring through thermal imagery (Jones, 1999; Möller et al., 2007); and plant transpiration estimations by sap flow (SF) sensor (Fernández et al., 2001; Giorio and Giorio, 2003; Granier, 1987). Among these techniques, SF measurement has two advantages for practical application. One is the simple structure of the sensor, a Granier-type sensor consists of a thermocouple and heater wires (Granier, 1987), and the other is durability: the SF sensor can generate measurements for several months without maintenance.

Fernández et al. (2001) proposed three strategies for an automatic irrigation system based on SF: (I) estimation of the total water consumed by representative trees in an orchard, (II) monitoring of water-deficit stressinduced changes in the hydraulic behavior of the tree, 
with the shape of the SF profile used as a sign of waterdeficit stress, and (III) monitoring of the relative reduction ratio of the daily total SF values of waterstressed plants to fully irrigated plants in the same orchard. Several studies have been conducted to detect water stress based on strategy I or III in peach (Conejero et al., 2007a, b; Remorini and Massai, 2003), olive (Giorio and Giorio, 2003), grape (Eastham and Gray, 1998; Ginestar et al., 1998), and banana (Lu et al., 2002); however, the precise estimation of whole plant water use involves errors of variation caused by the insertion depth and azimuth position of the sensor (Fernández et al., 2001; González-Altozano, 2008). Therefore, strategies I and III require a large number of sensors for an accurate estimation of the transpiration of a tree. Moreover, in strategy III, fully irrigated plants are also needed as reference trees (Conejero et al., 2007a, b). Regarding strategy II, Remorini and Massai (2003) indicated that $\mathrm{SF}$ velocity in stressed peach trees reached a peak in the morning $(10: 00 \mathrm{~h})$ and decreased thereafter, while irrigated trees maintained elevated water consumption even in the middle of the day. They concluded that the daily SF profile was a more sensitive indicator than daily total SF. In the current study, we tried to detect water-deficit stress based on strategy II, which has two merits for practical use: changes in the shape of the daily SF profile can be compared using the same sensor over time, and a fully irrigated tree is unnecessary as a reference. Because no index derived from the daily SF profile for irrigation has been described, the goal of this study is to find an index from the daily SF profile pattern for precise irrigation management.

When the daily SF profile is used to detect water stress, the effects of atmospheric conditions on the SF profile must be considered because SF is dependent on atmospheric conditions (Jones, 2004). On cloudy days, the stomata close and SF decreases even if the plants are not in a water-deficit condition. The reduction of SF by atmospheric conditions causes substantial errors in the detection of water-deficit stress. In this study, we tried to correct errors in SF data caused by the following atmospheric conditions: light intensity, vapor-pressure deficit (VPD), air temperature, and relative humidity.

For the precise assessment of plant water status, trees showing a clear water status are needed; therefore, in this study, peach trees grown in special large beds $(1500 \mathrm{~L})$ in a plastic greenhouse to avoid rainfall and groundwater effects were used to obtain precise waterdeficit conditions. We also measured predawn leaf water potential $\left(\Psi_{\mathrm{PD}}\right)$ and micrometric trunk circumference fluctuations for reference.

\section{Materials and Methods}

\section{Plant materials and treatments}

This experiment was conducted from September 20 to October 9, 2006. Two 8-year-old peach trees (Prunus persica (L.) Batsch cv. 'Hakuho' grafted on
'Ohatsumomo' peach), planted in $1500 \mathrm{~L}$ beds in a plastic greenhouse in Akitsu, Higashi-Hiroshima, Japan, were used in this study. The soil depth of each bed was $30 \mathrm{~cm}$. Trees were trained to a trellis with a single vertical trunk and 2 main horizontal branches. The trunk length was $1 \mathrm{~m}$, and each main branch length was $5 \mathrm{~m}$. Canopy area of each tree was $30 \mathrm{~m}^{2}$. The trunk diameter and circumference were 13 and $40 \mathrm{~cm}$, respectively. A compound fertilizer containing 64, 40, and $56 \mathrm{~g}$ of $\mathrm{N}$, $\mathrm{P}_{2} \mathrm{O}_{5}$, and $\mathrm{K}_{2} \mathrm{O}$, respectively, per bed was applied on September 5. One tree received wet treatment; the other tree received dry treatment. In both treatments, $75 \mathrm{~L}$ water was automatically applied when the soil water potentials (SWP) by tensiometer reached $-0.006 \mathrm{MPa}$ and $-0.049 \mathrm{MPa}$, respectively.

Measurements of predawn leaf water potential, soil water potential, and vapor pressure deficit

$\Psi_{\mathrm{PD}}$ was measured from October 3 to October 9 using a pressure chamber (DIK-700, Daiki Rika Kogyo Co., Ltd., Saitama, Japan) between 03:30 h and 04:00 h each day. Five leaves were used for each measurement. The soil water potential at a depth of $15 \mathrm{~cm}$ was monitored every 10 minutes with a tensiometer (DM-8HG, Takemura Denki Seisakusho Co., Ltd., Tokyo, Japan), which had a digital output connected to a voltage recorder (VR-71, T\&D Co., Ltd., Nagano, Japan). The vapor pressure deficit was calculated from temperature and relative humidity recorded every 10 minutes on a data logger (Type 3641, Hioki Co., Ltd., Nagano, Japan).

\section{Measurements of sap flow velocity, trunk circumference, and light intensity}

Sap flow velocity (SFV), trunk circumference fluctuation (TCF), and photosynthetic photon flux density (PPFD) were measured every 5 seconds, and the data logger (CR1000, Campbell Scientific Co., Ltd., Logan, USA) was programmed to record 10-min means. SFV was measured by the thermal dissipation method with a Granier-type sensor (Granier, 1987). Each sensor consisted of a pair of probes $20 \mathrm{~mm}$ long and $2 \mathrm{~mm}$ in diameter. Each probe was inserted $10 \mathrm{~cm}$ apart on the trunk at about $1 \mathrm{~m}$ above the ground $(0.7 \mathrm{~m}$ above the bed surface). The upper probe included a heater that was supplied with $0.2 \mathrm{~W}$ constant power. The temperature difference between the upper heated probe and the lower unheated reference probe was measured and converted to SFV according to Granier's equation (Granier, 1987). PPFD was measured by a quantum light sensor (LI-190; Li-Cor Co., Ltd., Lincoln, USA).

Micrometric trunk circumference fluctuations were measured with a set of linear variable displacement transducers (LVDTs) (Type DC, accuracy $\pm 2 \mu \mathrm{m}$; UP Co., Ltd., Cottbus, Germany). The LDVTs were attached to the trunk with a bracket. Maximum daily shrinkage (MDS) of the trunk was calculated as the difference between the maximum and minimum daily trunk circumferences. 

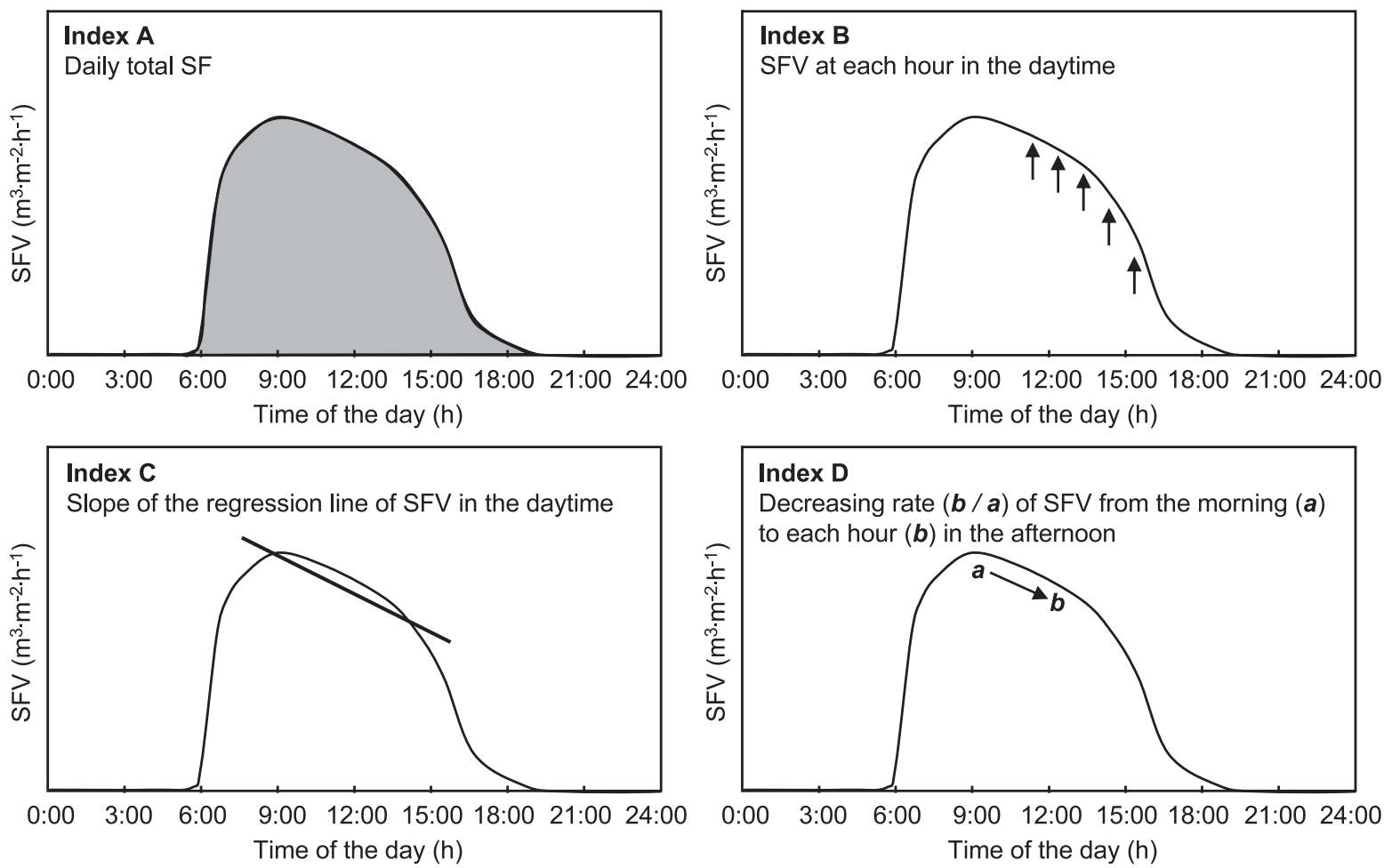

Fig. 1. Four SF indices were compared to detect water-deficit stress. Index A is daily total SF, which is the integration of every 10-min SFV. Index B is SFV at each hour (average values for 1 hour from 11:00 to 16:00 h). Index C is the slope of the regression line between SFV and daytime during 07:00-17:00 $\mathrm{h}$ or 10:00-15:00 $\mathrm{h}$. Index D is the decreasing rate of SFV at each hour (average values for 1 hour during 11:00-16:00 h) from the morning (average value from 07:00 to 11:00 h).

Four indices were used to detect water-deficit stress by comparing MDS and $\Psi_{\mathrm{PD}}$ (Fig. 1). Index A is daily total SF, which is the integration of every 10 -min SFV. Index B is SFV at each hour (average values for 1 hour from 11:00 to $16: 00 \mathrm{~h}$ ). Index $\mathrm{C}$ is the slope of the regression line between SFV and daytime at 07:00 $17: 00 \mathrm{~h}$ or $10: 00-15: 00 \mathrm{~h}$. Index $\mathrm{D}$ is the decreasing rate of SFV each hour (average values for 1 hour during 11:00-16:00 h) from the morning (average value from 07:00 to $11: 00 \mathrm{~h}$ ).

Two methods of correction by PPFD were tested to eliminate atmospheric errors. One method was correction using the logarithmic regression curve (LOG). In LOG correction for the calculation of SF indices, rates of SFV from the expected SFV were used instead of measured SFV values. The rates of SFV were derived by dividing measured SFV by the expected SFV at each PPFD. The expected SFV was derived by a regression equation $(y$ $=0.0276 \operatorname{Ln}(x)-0.0905$, where $y$ is the expected SFV and $x$ is the measured PPFD) (see Fig. 4A). The other method was saturated PPFD correction (SAT), in which $\mathrm{SF}$ values were used only when PPFDs were over the saturation point of $800 \mu \mathrm{mol} \cdot \mathrm{m}^{-2} \cdot \mathrm{s}^{-1}$ (see Fig. $4 \mathrm{~A}$ ) for the calculation of SF indices.

\section{Results}

Although the absolute values of SFV were slightly higher in the dry treatment than in the wet treatment condition, the daily profiles of SFV were exactly the same between October 3 and October 6 (Fig. 2A, B). From October 7, five days after starting to withhold irrigation, the SFV in the afternoon started to decrease in the dry treatment compared to the wet treatment condition. $\Psi_{\mathrm{PD}}$ and SWP decreased to $-0.56 \mathrm{MPa}$ and $-0.03 \mathrm{Mpa}$, respectively, on October 7 in the dry treatment (Fig. 2C, D). SFV decreased on October 5 and October 6, both cloudy days, and the reductions corresponded to the depletion of PPFD and vapor pressure deficit (Fig. 2A, B, E, F).

The relationship between SFV and TCF in the dry treatment on fair-weather days is shown in Figure 3. SFV in the afternoon decreased from September 26 (Fig. 3A). On that day, the trunk shrank greatly from the morning to the afternoon, and SWP decreased to under $-0.03 \mathrm{MPa}$ (Fig. 3B, C).

The relationship between SFV and meteorological factors, i.e., PPFD, temperature, relative humidity, and VPD, in the wet treatment from September 20 to October 9 is shown in Figure 4. Under non-water-stressed conditions, SFVs were stable when PPFDs were constant; however, SFVs were broadly distributed even though temperatures, relative humidities and VPDs were constant. The coefficient of the logarithm correlation between PPFD and SFV was $r^{2}=0.84^{* *}$, which was the highest value among the meteorological factors estimated. 

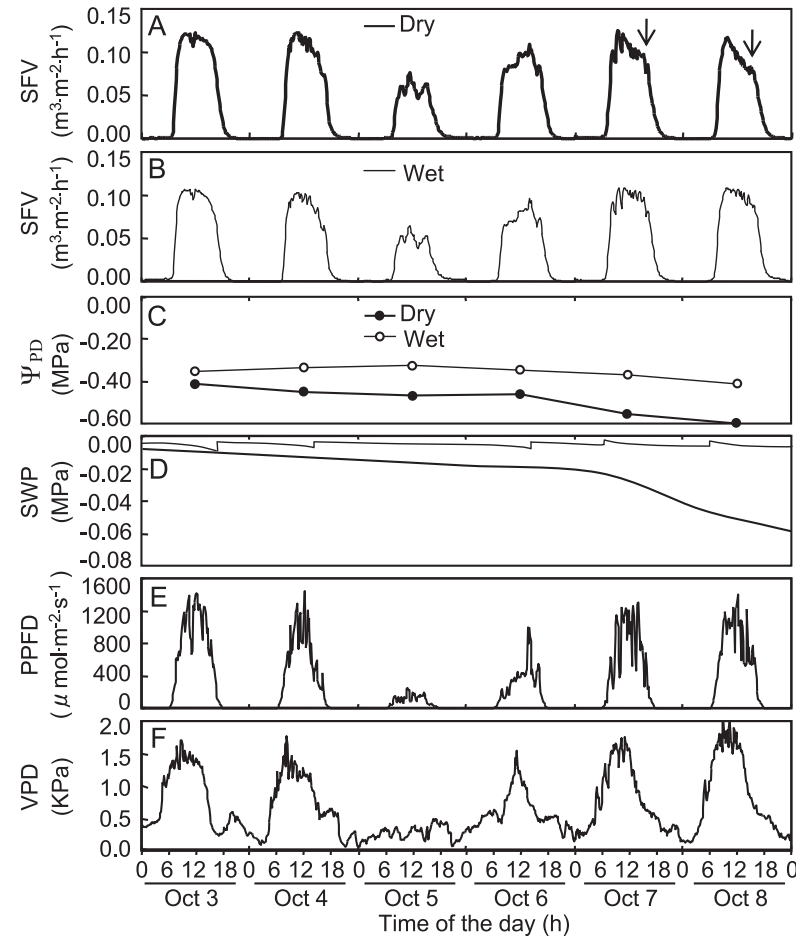

Fig. 2. Diurnal courses of sap flow velocity (SFV), predawn leaf water potential $\left(\Psi_{\mathrm{PD}}\right)$ and soil water potential $(\mathrm{SWP})$ in dry and wet treatments in relation to photosynthetic photon flux density (PPFD) and vapor pressure deficit (VPD) from October 3 to October 8. A and B are SFV in each treatment. C, D, E, and F are $\Psi_{\mathrm{PD}}, \mathrm{SWP}, \mathrm{PPFD}$, and VPD, respectively. Bold and thin lines in A, B, C, and D indicate dry and wet treatments, respectively. Arrows indicate the depression of SFV in dry treatment.

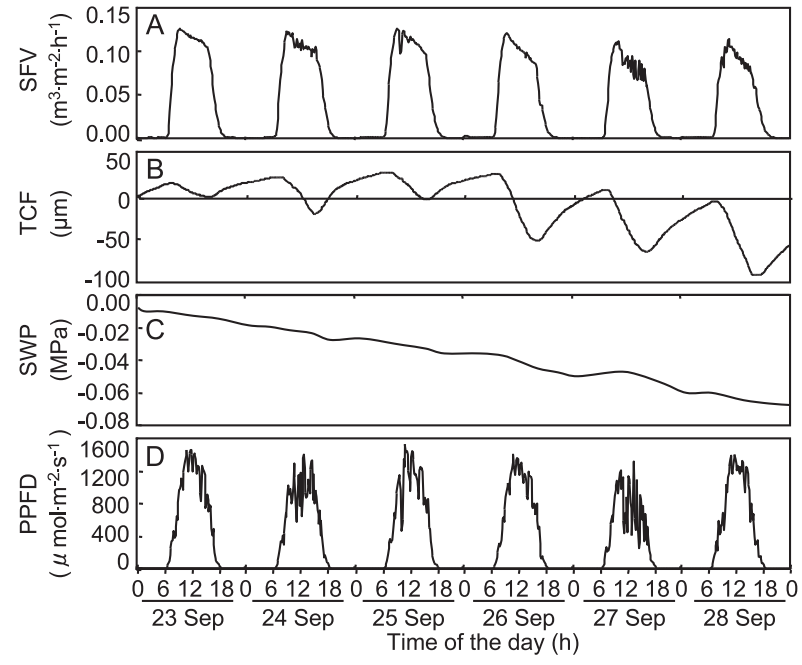

Fig. 3. Diurnal courses of sap flow velocity (SFV), trunk circumference fluctuation (TCF), soil water potential (SWP), and photosynthetic photon flux density (PPFD) in the dry treatment (September 23 to 28). A, B, C, and D are SFV, TCF, SWP, and PPFD, respectively.

Four SF indices and those corrected by PPFD were demonstrated to detect water stress by comparing two indicators: maximum daily shrinkage of trunk (MDS) and $\Psi_{\mathrm{PD}}$. The details of four SF indices are shown in Figure 1. When corrections of SFV by PPFD were not applied (NC: no correction), correlation coefficients between MDS and index A (daily total SF) and index $\mathrm{B}$ (SFV at each hour in the daytime) were low and not significant (Table 1). Correlation coefficients between MDS and index $\mathrm{C}$ (slopes of the regression lines between

Table 1. Correlation coefficients $\left(r^{2}\right)$ between maximum daily shrinkage of trunk (MDS) and SF-derived indices with or without correction by PPFD.

\begin{tabular}{|c|c|c|c|c|c|c|}
\hline \multirow{2}{*}{$\begin{array}{c}\text { Correction by } \\
\text { PPFD }^{z}\end{array}$} & \multirow{2}{*}{$\begin{array}{c}\text { Index A (daily } \\
\text { total SF) }\end{array}$} & \multicolumn{5}{|c|}{ Index B (SFV at each hour) } \\
\hline & & $11: 00-12: 00 \mathrm{~h}$ & $12: 00-13: 00 \mathrm{~h}$ & $13: 00-14: 00 \mathrm{~h}$ & $14: 00-15: 00 \mathrm{~h}$ & $15: 00-16: 00 \mathrm{~h}$ \\
\hline $\mathrm{NC}$ & 0.06 & 0.01 & 0.01 & 0.00 & 0.01 & 0.01 \\
\hline (n) & (20) & (20) & $(20)$ & (20) & (20) & $(20)$ \\
\hline LOG & 0.00 & $0.27 * y$ & $0.44 * *$ & $0.49 * *$ & $0.61 * *$ & $0.40 * *$ \\
\hline (n) & (20) & $(20)$ & $(20)$ & (20) & (20) & $(20)$ \\
\hline SAT & 0.02 & $0.56^{* *}$ & $0.66^{* *}$ & $0.55^{* *}$ & $0.69 * *$ & $0.81 * *$ \\
\hline (n) & (18) & (17) & (16) & (18) & (17) & (7) \\
\hline
\end{tabular}

\begin{tabular}{|c|c|c|c|c|c|c|c|}
\hline \multirow{2}{*}{$\begin{array}{c}\text { Correction by } \\
\text { PPFD }\end{array}$} & \multicolumn{2}{|c|}{ Index $\mathrm{C}$ (slope of the regression line) } & \multicolumn{5}{|c|}{ Index D (decreasing rate of SFV from the morning to each hour in the afternoon) } \\
\hline & 07:00-17:00 h & $10: 00-15: 00 \mathrm{~h}$ & $11: 00-12: 00 \mathrm{~h}$ & $12: 00-13: 00 \mathrm{~h}$ & $13: 00-14: 00 \mathrm{~h}$ & $14: 00-15: 00 \mathrm{~h}$ & $15: 00-16: 00 \mathrm{~h}$ \\
\hline $\mathrm{NC}$ & $0.58 * *$ & $0.44 * *$ & $0.37 * *$ & $0.34 * *$ & $0.38 * *$ & $0.44 * *$ & $0.34 * *$ \\
\hline (n) & (20) & (20) & (20) & (20) & (20) & (20) & $(20)$ \\
\hline LOG & $0.34 * *$ & 0.02 & $0.36^{* *}$ & $0.27 *$ & $0.22 *$ & $0.28^{*}$ & $0.27 *$ \\
\hline (n) & (20) & (20) & (20) & $(20)$ & (20) & (20) & $(20)$ \\
\hline SAT & $0.62 * *$ & $0.62 * *$ & $0.52 * *$ & $0.76^{* *}$ & $0.77 * *$ & $0.58 * *$ & 0.29 \\
\hline (n) & (18) & (18) & (17) & (16) & (17) & (16) & (6) \\
\hline
\end{tabular}

${ }^{z}$ NC, No correction by PPFD; LOG, Using the rates of expected SFV derived from the logarithmic regression curve between PPFD and SF in Figure 4 for index calculation; SAT, Using SF values only when PPFDs were over the saturation point of $800 \mu \mathrm{mol} \cdot \mathrm{m}^{-2} \cdot \mathrm{s}^{-1}$ for index calculation from September 20 to October 9 in 2006.

$\mathrm{y} * *$ and $*$ indicate significance at $1 \%$ and $5 \%$, respectively. 
Table 2. Correlation coefficients $\left(r^{2}\right)$ between predawn leaf water potential $\left(\Psi_{\mathrm{PD}}\right)$ and SF-derived indices with or without correction by PPFD.

\begin{tabular}{|c|c|c|c|c|c|c|}
\hline \multirow{2}{*}{$\begin{array}{l}\text { Correction by } \\
\text { PPFD }^{z}\end{array}$} & \multirow{2}{*}{$\begin{array}{l}\text { Index A (daily } \\
\quad \text { total SF) }\end{array}$} & \multicolumn{5}{|c|}{ Index B (SFV at each hour) } \\
\hline & & $11: 00-12: 00 \mathrm{~h}$ & 12:00-13:00 h & $13: 00-14: 00 \mathrm{~h}$ & $14: 00-15: 00 \mathrm{~h}$ & $15: 00-16: 00 \mathrm{~h}$ \\
\hline $\mathrm{NC}$ & 0.03 & 0.03 & 0.09 & 0.12 & 0.15 & 0.10 \\
\hline (n) & (7) & (7) & (7) & (7) & (7) & (7) \\
\hline LOG & 0.02 & 0.10 & 0.35 & $0.59^{*}$ & $0.58^{*}$ & 0.07 \\
\hline (n) & (7) & (7) & (7) & (7) & (7) & (7) \\
\hline SAT & 0.03 & $0.88^{* y}$ & $0.96^{* *}$ & $0.86^{* *}$ & $0.88^{*}$ & - \\
\hline (n) & (6) & (5) & (5) & (6) & (5) & (1) \\
\hline
\end{tabular}

\begin{tabular}{|c|c|c|c|c|c|c|c|}
\hline \multirow{2}{*}{$\begin{array}{c}\text { Correction by } \\
\text { PPFD }\end{array}$} & \multicolumn{2}{|c|}{ Index $\mathrm{C}$ (slope of the regression line) } & \multicolumn{5}{|c|}{ Index D (decreasing rate of SFV from the morning to each hour in the afternoon) } \\
\hline & $07: 00-17: 00 \mathrm{~h}$ & $10: 00-15: 00 \mathrm{~h}$ & $11: 00-12: 00 \mathrm{~h}$ & $12: 00-13: 00 \mathrm{~h}$ & $13: 00-14: 00 \mathrm{~h}$ & $14: 00-15: 00 \mathrm{~h}$ & $15: 00-16: 00 \mathrm{~h}$ \\
\hline $\mathrm{NC}$ & 0.41 & 0.28 & 0.04 & 0.38 & 0.40 & 0.19 & 0.18 \\
\hline (n) & (7) & (7) & (7) & (7) & (7) & (7) & (7) \\
\hline LOG & 0.04 & 0.03 & 0.06 & 0.28 & 0.06 & 0.23 & 0.06 \\
\hline (n) & (7) & (7) & (7) & (7) & (7) & (7) & (7) \\
\hline SAT & $0.88 * *$ & $0.85^{* *}$ & $0.83^{*}$ & $0.92 * *$ & $0.88^{*}$ & 0.86 & - \\
\hline (n) & (6) & (6) & (5) & (5) & (5) & (4) & (1) \\
\hline
\end{tabular}

${ }^{z}$ NC, No correction by PPFD; LOG, Using the rates of expected SFV derived from the logarithmic regression curve between PPFD and SF in Figure 4 for index calculation; SAT, Using SF values only when PPFDs were over the saturation point of $800 \mu \mathrm{mol} \cdot \mathrm{m}^{-2} \cdot \mathrm{s}^{-1}$ for index calculation from September 20 to October 9 in 2006.

$\mathrm{y} * *$ and $*$ indicate significance at $1 \%$ and $5 \%$, respectively.

SFV and two terms of daytime) and index D (decreasing rates of SFV from the morning to each hour in the afternoon) were higher than indices A and B at every hour, and they were significant (Table 1). Correlation coefficients between MDS and index B were improved by the LOG correction; however, LOG correction did not increase correlation coefficients between MDS and indices A, C, and D. The application of SAT correction improved all correlation coefficients between MDS and SF indices except indices A and D at 15:00-16:00 h (Table 1). When SAT correction was applied, the number of available data decreased because PPFDs decreased under $800 \mu \mathrm{mol} \cdot \mathrm{m}^{-2} \cdot \mathrm{s}^{-1}$ when the weather was cloudy. Especially, the data at 15:00-16:00 h, close to sunset, of indices B and D in SAT correction were greatly reduced.

Correlation coefficients of $\Psi_{\mathrm{PD}}$ to SF indices showed tendencies similar to those of MDS, although the number of data was fewer than that of MDS (Table 2). Correlation coefficients for 13:00-14:00 $\mathrm{h}$ and 14:00-15:00 $\mathrm{h}$ in index B with LOG correction, all hours in indices B and C with SAT correction, and index D except for 14:0015:00 $\mathrm{h}$ with SAT correction were significant.

\section{Discussion}

\section{Effects of atmospheric factors on $S F$}

SF showed a significant correlation with atmospheric factors such as relative humidity, air temperature, VPD, and PPFD (Fig. 4). These results are in accordance with previous results of transpiration measurements in almond trees (Romero and Botía, 2006). Among these factors, PPFD clearly showed the highest correlation with SFV, which increased with increasing PPFD and became saturated at around $800 \mu \mathrm{mol} \cdot \mathrm{m}^{-2} \cdot \mathrm{s}^{-1}$. This saturation point is almost the same as that for photosynthesis in peach (Nii, 1993). As for short-term changes, the decreased SFV corresponded to sudden PPFD reduction around noon on October 3 (Fig. 2), although VPD did not decrease at that time. The effects of air humidity on the transpiration rate varied among species, and transpiration did not increase linearly with decreasing air humidity in Prunus armeniaca (Schulze, 1986). This phenomenon may be the reason for the relatively low correlation between SFV and VPD. These results indicate that SFV is affected more by PPFD changes than by VPD under well-watered conditions; therefore, the correction of SFV by PPFD is considered adaptable for the detection of water-deficit stress.

\section{Correction of SFV by PPFD}

Correction of SFV by PPFD enhanced the correlation coefficients between SF indices and water status parameters such as MDS and $\Psi_{\mathrm{PD}}$ (Tables 1 and 2), and SAT correction improved them more than LOG correction. In LOG correction, SFVs were used to detect water deficit stress even though PPFDs were under $800 \mu \mathrm{mol} \cdot \mathrm{m}^{-2} \cdot \mathrm{s}^{-1}$; however, SFVs at low PPFDs varied greatly, i.e., SFV at $400 \mu \mathrm{mol} \cdot \mathrm{m}^{-2} \cdot \mathrm{s}^{-1}$ of PPFD showed around a twofold greater variation than that at 800 $\mu \mathrm{mol} \cdot \mathrm{m}^{-2} \cdot \mathrm{s}^{-1}$ of PPFD even in well-watered conditions (Fig. 4). Hence, SFVs under $800 \mu \mathrm{mol} \cdot \mathrm{m}^{-2} \cdot \mathrm{s}^{-1}$ of PPFDs were excluded for SAT correction, causing a higher correlation in SAT correction than in LOG.

One problem with SAT correction is that water-deficit stress cannot be calculated when PPFDs are low, as they are on cloudy or rainy days. The number of days on which the water-deficit stress index could be calculated 

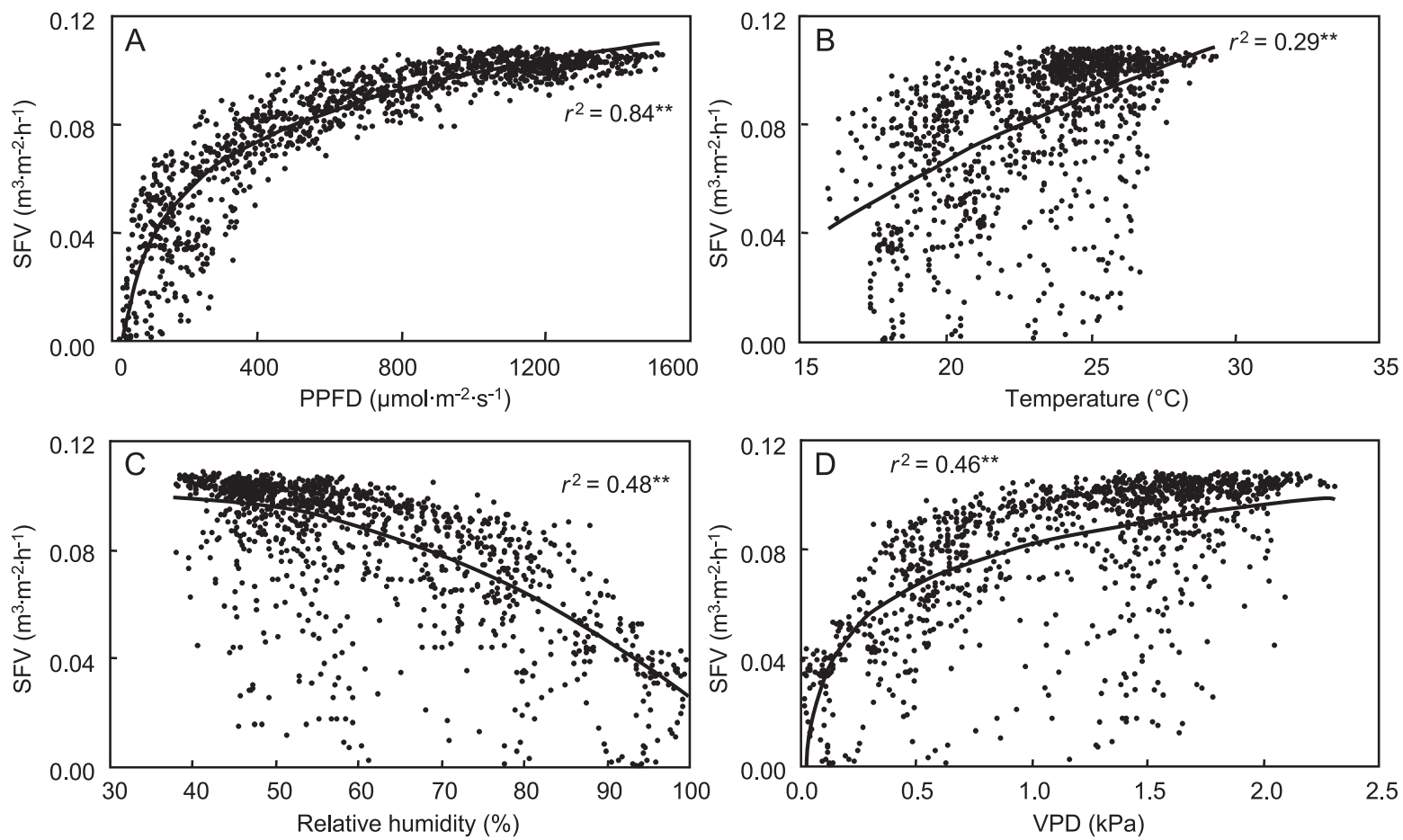

Fig. 4. Relationships between sap flow velocity (SFV) and photosynthetic photon flux density (PPFD), air temperature, relative humidity, and vapor pressure deficit (VPD) in the wet treatment. A, B, C, and D are PPFD, temperature, relative humidity, and VPD, respectively. Regression curves in PPFD, temperature, and VPD were obtained from logarithmic correlation. Regression curves in relative humidity were obtained from polynomial correlations. Correlation coefficients with $* *$ indicate significance $(P<0.01)$.

fell 10 to $20 \%$ during the experiment when SAT correction was applied (Tables 1 and 2). At 15:00$16: 00 \mathrm{~h}$, only $20 \%$ of the data were available in indices $\mathrm{B}$ and $\mathrm{D}$ because it was close to sunset. These results show the limitation of SAT correction; however, when it is cloudy or rainy, plants will not suffer from severe water-deficit stress, so this limitation becomes problematic only when a low PPFD continues for several days.

\section{Comparison of indices}

Remorini and Massai (2003) reported that the daily total SF decreased greatly in stressed peach trees but that daily total SF was a less sensitive indicator than daily SF profiles; however, in the present study, daily total SF did not decrease greatly (Figs. 2 and 3 ) and did not correlate with MDS and $\Psi_{\mathrm{PD}}$ (index A in Tables 1 and 2). This inconsistency could have been caused by the difference in the strength of water-deficit stress. In the study by Remorini and Massai (2003), $\Psi_{\mathrm{PD}}$ in stressed trees decreased around $-1.0 \mathrm{MPa}$; however, in our study, $\Psi_{\mathrm{PD}}$ did not decrease under $-0.6 \mathrm{MPa}$ (Fig. 2). Goldhamer et al. (1999) showed that peach fruit size was significantly reduced in severe water-deficit conditions when $\Psi_{\mathrm{PD}}$ was under $-1.0 \mathrm{MPa}$. To control irrigation without fruit size reduction, the onset of waterdeficit stress must be detected by SF, and $\Psi_{\mathrm{PD}}$ should be kept over $-1.0 \mathrm{MPa}$. In the present study, relatively mild water-deficit stress $\left(\Psi_{\mathrm{PD}}\right.$ was over $\left.-0.6 \mathrm{MPa}\right)$ was detected by indices $\mathrm{C}$ and $\mathrm{D}$, which were based on daily
SF profiles. Under these mild stress conditions, SFVs increased in the morning and decreased thereafter. These results are consistent with those of previous reports (Correia et al., 1997; Xiloyannis et al., 1980) which indicated that transpiration in the afternoon decreased in non-irrigated peach trees but that morning transpiration did not differ between irrigated and non-irrigated trees. Correia et al. (1997) indicated that this daily pattern of the transpiration rate in peach is associated with low stomatal sensitivity to abscisic acid (ABA) during the first hours of the day where ABA is a major regulator of stomatal responses under water stress (Tardieu and Davies, 1992).

From these results, it is concluded that the indices of daily SF patterns, such as indices $\mathrm{C}$ and $\mathrm{D}$, which show a decrease in SFV from the morning to the afternoon, are suitable for detecting water stress; furthermore, water stress can be detected based on SF changes when SFVs under low PPFDs $\left(<800 \mu \mathrm{mol} \cdot \mathrm{m}^{-2} \cdot \mathrm{s}^{-1}\right)$ are eliminated. The best index to detect water-deficit stress is the decreasing rate of SFV from the morning (07:0011:00 h) to that at any hour from $12: 00 \mathrm{~h}$ to $15: 00 \mathrm{~h}$ with correction by SAT. Moreover, the detection of waterdeficit stress from continuous data collected on the same sensor enables the elimination of fully irrigated reference plants and errors caused by individual SF sensor variations and insertion conditions. As a further expected application of the indices, $\Psi_{\mathrm{PD}}$ can be estimated from the indices. The regression equation between index D 
(12:00-13:00 h) with SAT correction and $\Psi_{\mathrm{PD}}$, which showed a high correlation coefficient $\left(r^{2}=0.92 * *\right)$, is derived as follows, $y=1.11 x-1.55$, where $y$ is $\Psi_{\mathrm{PD}}$ and $x$ is the index; however, to confirm this relation, more measurements should be conducted.

In the current study, peach trees grown in special large beds $(1500 \mathrm{~L})$ in a plastic greenhouse to avoid rainfall and groundwater effects were used to obtain the precise water-deficit status. Because of the limitation of the experimental conditions, only one tree per treatment was available; however, the daily profiles of the SFVs of two trees were exactly the same during non-water stressed periods (Fig. 2A, B). This very high correspondence confirmed the precise estimation of SF and tree water status in this study. The results of this study showed a theoretical and adaptive method to detect water-deficit stress from daily SF profiles. Practical application of the proposed SF index for peach cultivation was conducted the following year (Hamana et al., 2008). The preliminary results show the possibility that irrigation based on index D with SAT correction throughout the growing period reduces excessive water supply and increases fruit sugar content without negative effects on tree growth; however, these results as well as the results in the present study were limited by the circumstances, season, and tree conditions. Therefore, further studies are needed to determine the practical use of the proposed method.

\section{Acknowledgments}

We would like to thank Dr. K. Morinaga for valuable suggestions. We also wish to thank Mr. N. Karata for technical assistance.

\section{Literature Cited}

Conejero, W., J. J. Alarcón, Y. García-Orellana, J. M. Abrisqueta and A. Torrecillas. 2007a. Daily sap flow and maximum daily trunk shrinkage measurements for diagnosing water stress in early maturing peach trees during the post-harvest period. Tree Physiol. 27: 81-88.

Conejero, W., J. J. Alarcón, Y. García-Orellana, E. Nicolás and A. Torrecillas. 2007b. Evaluation of sap flow and trunk diameter sensors for irrigation scheduling in early maturing peach trees. Tree Physiol. 27: 1753-1759.

Correia, M. J., M. L. Rodorigues, M. I. Ferreira and J. S. Pereira. 1997. Diurnal change in the relationship between stomatal conductance and abscisic acid in the xylem sap of field-grown peach trees. J. Exp. Bot. 48: 1727-1736.

Eastham, J. and S. Gray. 1998. A preliminary evaluation of the suitability of sap flow sensors for use in scheduling vineyard irrigation. Am. J. Enol. Vitic. 49: 171-176.

Fernández, J. E., M. J. Palomo, A. Díaz-Espejo, B. E. Clothier, S. R. Green, I. F. Girón and F. Moreno. 2001. Heat-pulse measurements of sap flow in olives for automating irrigation: tests, root flow and diagnostics of water stress. Agric. Water Manage. 51: 99-123.

Ginestar, C., J. Eastham, S. Gray and P. Iland. 1998. Use of sapflow sensors to schedule vineyard irrigation. I. Effects of post-veraison water deficits on water relations, vine growth, and yield of Shiraz grapevines. Am. J. Enol. Vitic. 49: 413420.

Giorio, P. and G. Giorio. 2003. Sap flow of several olive trees estimated with the heat-pulse technique by continuous monitoring of a single gauge. Environ. Exp. Bot. 49: 9-20.

Goldhamer, D. A. and E. Fereres. 2001. Irrigation scheduling protocols using continuously recorded trunk diameter measurement. Irrig. Sci. 20: 115-125.

Goldhamer, D. A., E. Fereres, M. Mata, J. Girona and M. Cohen. 1999. Sensitivity of continuous and discrete plant and soil water status monitoring in peach trees subjected to deficit irrigation. J. Amer. Soc. Hort. Sci. 124: 437-444.

González-Altozano, P., E. W. Pavel, J. A. Oncins, J. Doltra, M. Cohen, T. Paço, R. Massai and J. R. Castel. 2008. Comparative assessment of five methods of determining sap flow in peach trees. Agric. Water Manage. 95: 503-515.

Granier, A. 1987. Evaluation of transpiration in a Douglas-fir stand by means of sap flow measurements. Tree Physiol. 3: 309320.

Hamana, Y., T. Yamane and M. Nakano. 2008. Practicability of an irrigation method based on the decreasing rate of sap flow velocity in peach tree. Hort. Res. (Japan) 7 (Suppl. 2): 157 (In Japanese).

Jones, H. G. 1999. Use of infrared thermometry for estimation of stomatal conductance as a possible aid to irrigation scheduling. Agric. For. Meteorol. 95: 139-149.

Jones, H. G. 2004. Irrigation scheduling: advantages and pitfalls of plant-based methods. J. Exp. Bot. 55: 2427-2436.

Link, S. O., M. E. Thiede and M. G. van Bavel. 1998. An improved strain-gauge device for continuous field measurement of stem and fruit diameter. J. Exp. Bot. 49: 1583-1587.

Lu, P., K. C. Woo and Z. T. Liu. 2002. Estimation of whole-plant transpiration of bananas using sap flow measurements. J. Exp. Bot. 53: 1771-1779.

Möller, M., V. Alchanatis, Y. Cohen, M. Meron, J. Tsipris, A. Naor, V. Ostrovsky, M. Sprintsin and S. Cohen. 2007. Use of thermal and visible imagery for estimating crop water status of irrigated grapevine. J. Exp. Bot. 58: 827-838.

Nii, N. 1993. Fruiting effects of leaf characteristics, photosynthesis, and root growth in peach tree. J. Japan. Soc. Hort. Sci. 62: $519-526$.

Parker, M. L., J. Hull and R. L. Perry. 1993. Orchard floor management affects peach rooting. J. Amer. Soc. Hort. Sci. 118: 714-718.

Remorini, D. and R. Massai. 2003. Comparison of water status indicators for young peach trees. Irrig. Sci. 22: 39-46.

Romero, P. and P. Botía. 2006. Daily and seasonal patterns of leaf water relations and gas exchange of regulated deficit-irrigated almond trees under semiarid conditions. Environ. Exp. Bot. 56: $158-173$.

Schulze, E. D. 1986. Carbon dioxide and water vapor exchange in response to drought in the atmosphere and in the soil. Ann. Rev. Plant Physiol. 37: 247-274.

Tardieu, F. and W. J. Davies. 1992. Stomatal response to abscisic acid is a function of current plant water status. Plant Physiol. 98: $540-549$.

Xiloyannis, C., K. Uriu and G. C. Martin. 1980. Seasonal and diurnal variations in abscisic acid, water potential, and diffusive resistance in leaves from irrigated and non-irrigated peach trees. J. Amer. Soc. Hort. Sci. 105: 412-415.

Yamane, T., K. Shibayama, Y. Hamana and H. Yakushiji. 2009. Response of container-grown girdled grapevines to short-term water-deficit stress. Am. J. Enol. Vitic. 60: 50-56. 